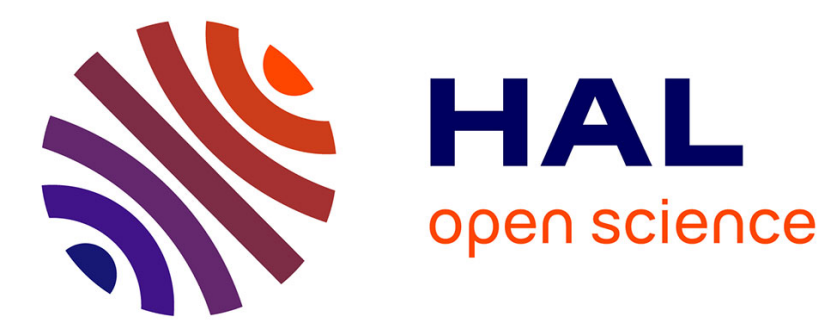

\title{
Fragility curves for risk-targeted seismic design maps
}

Thomas Ulrich, Caterina Negulescu, John Douglas

\section{To cite this version:}

Thomas Ulrich, Caterina Negulescu, John Douglas. Fragility curves for risk-targeted seismic design maps. Bulletin of Earthquake Engineering, 2014, 12 (4), pp.1479-1491. 10.1007/s10518-013-9572-y . hal-00919111

\section{HAL Id: hal-00919111 https://hal-brgm.archives-ouvertes.fr/hal-00919111}

Submitted on 16 Dec 2013

HAL is a multi-disciplinary open access archive for the deposit and dissemination of scientific research documents, whether they are published or not. The documents may come from teaching and research institutions in France or abroad, or from public or private research centers.
L'archive ouverte pluridisciplinaire HAL, est destinée au dépôt et à la diffusion de documents scientifiques de niveau recherche, publiés ou non, émanant des établissements d'enseignement et de recherche français ou étrangers, des laboratoires publics ou privés. 
1 Fragility curves for risk-targeted seismic design maps

2 Thomas Ulrich*, Caterina Negulescu and John Douglas

$3 *=$ corresponding author

$4 \quad \mathrm{BRGM}-\mathrm{DRP} / \mathrm{RSV}$

$5 \quad 3$ avenue C. Guillemin

$6 \quad$ BP 36009

745060 ORLEANS Cedex 2

8 France

$9 \quad$ Telephone (corresponding author): $+33(0) 2.38 .64 .34 .38$

10

Fax (corresponding author): +33 (0)2.38.64.47.38

11 Email (corresponding author): t.ulrich@brgm.fr

12 Submitted to Bulletin of Earthquake Engineering on $2^{\text {nd }}$ August 2013

13 Resubmitted after revisions on $28^{\text {th }}$ November 2013

14 
Seismic design using maps based on 'risk-targeting' would lead to an annual probability of attaining or exceeding a certain damage state that is uniform over an entire territory. These maps are based on convolving seismic hazard curves from a standard probabilistic analysis with the derivative of fragility curves expressing the chance for a code-designed structure to attain or exceed a certain damage state given a level of input motion (e.g. peak ground acceleration, PGA). There are few published fragility curves for structures respecting the Eurocodes (ECs, principally EC8 for seismic design) that can be used for the development of risk-targeted design maps for Europe. In this article a set of fragility curves for a regular three-storey reinforced-concrete building designed using EC2 and EC8 for medium ductility and increasing levels of design acceleration $\left(\mathrm{a}_{\mathrm{g}}\right)$ is developed. These curves show that structures designed using EC8 against PGAs up to about $1 \mathrm{~m} / \mathrm{s}^{2}$ have similar fragilities to those that respect only EC2 (although this conclusion may not hold for irregular buildings, other geometries or materials). From these curves, the probability of yielding for a structure subjected to a PGA equal to $\mathrm{a}_{\mathrm{g}}$ varies between $0.14\left(\mathrm{a}_{\mathrm{g}}=0.7 \mathrm{~m} / \mathrm{s}^{2}\right)$ and $0.85\left(\mathrm{a}_{\mathrm{g}}=3 \mathrm{~m} / \mathrm{s}^{2}\right)$ whereas the probability of collapse for a structure subjected to a PGA equal to $\mathrm{a}_{\mathrm{g}}$ varies between $1.7 \times 10^{-7}\left(\mathrm{a}_{\mathrm{g}}=0.7 \mathrm{~m} / \mathrm{s}^{2}\right)$ and $1.0 \times 10^{-5}\left(\mathrm{a}_{\mathrm{g}}=3\right.$ $\left.\mathrm{m} / \mathrm{s}^{2}\right)$

Keywords: seismic risk; fragility curves; Eurocode 8 (EC8); risk-targeting; reinforced concrete; Eurocode 2 (EC2)

\section{Introduction}

In the past decade the philosophy often known as risk-targeting has started to be employed to develop maps of design accelerations for use with seismic building codes (Luco et al., 2007; Luco, 2009). The aim of this method is to estimate seismic accelerations that, when used for design purposes, lead to a chosen level of risk (e.g. annual probability of collapse of $10^{-5}$ ) that is uniform over an entire territory. This procedure relies on convolving hazard curves from a standard probabilistic seismic hazard assessment with fragility curves that are a function of the design acceleration (e.g. buildings designed against a higher acceleration have fragility curves shifted to the right). This approach has recently been 
tested for mainland France by Douglas et al. (2013) with respect to the recent French seismic zonation to be used in conjunction with Eurocode 8 (EC8). Amongst other conclusions, they emphasized the lack of studies on how fragility curves change as a function of the design acceleration. This deficiency of knowledge is a current block on the adoption of risk-targeting for the next generation of seismic design codes.

The purpose of this article is to investigate the impact of the design acceleration on fragility curves by deriving such curves for a series of reinforced-concrete (RC) buildings designed using EC8 for different levels of earthquake loading. The next section presents the series of structures, emphasizing the parts of their design that are functions of the input acceleration. In Section 3 fragility curves are derived for these different structures using a standard technique based on dynamic nonlinear analysis using hundreds of input accelerograms. The influence of the design acceleration on the structure's fragility is discussed in the penultimate section along with how the results of this study influence the risk-targeting approach. The article ends with some brief conclusions and suggestions for future work.

\section{Eurocode 8-designed structures}

In the present study, a three storey ( $3 \mathrm{~m}$ high)-three bay (4 $\mathrm{m}$ long)-four frame (4 $\mathrm{m}$ long) RC structure is considered. This structure is, from our point of view, rather representative of modern European buildings. A regular structure is considered, so that simpler design procedures could be used (EC8 4.2.3): a $2 \mathrm{D}$ model instead of a more complex $3 \mathrm{D}$ model and the lateral force method instead of the more complex modal approach. In addition, EC8 4.2.1 advises to design structures to be as regular as possible, because irregularities may greatly affect the structure's seismic resistance. The building is considered to be a typical residential or office building (importance class 2 in EC 8, common buildings). In this section details of the design of this structure to conform to Eurocode 2 (EC2) (CEN, 2004a) and EC8 (CEN, 2004b) are provided.

The vulnerability of RC structures to earthquakes has been extensively studied in the past decades, with the development of reliable modelling tools, e.g. fibre based-models, with nonlinear behaviour of the materials composing the structural elements (Spacone et al., 1996). Nevertheless, they remain 
complex structures, with many geometrical intricacies, that are often neglected. Thus, the reinforcement varies along the beams as a function of the flexural moment. The stirrup density along the beams changes as well, to cope with the high shear solicitation near the columns. The joint zones, between columns and beams, can also present certain complexities, particularly the joint zones involving the side columns. In these zones, the beam reinforcing bars (rebars) are sometimes bent so that they are in the same direction as the column rebars, resulting in complex $3 \mathrm{D}$ joint zones. A final example of complex detailing is the intricate integration of the structural elements in the slabs, which generates a complex 3D structure in which the slabs play a non-negligible role.

In the present study, it has been decided not to use highly-refined models for two reasons. Firstly, no robust models have yet been developed to take account of some of these aforementioned complexities on earthquake response. Secondly, inclusion of these details would have meant the conception of very complex numerical models, requiring much care and time, and probably suffering from considerable numerical instabilities. Also, design choices would have been required, which could have led to overspecific models, less adapted to describe the generic response of structures. It is interesting to note that using more sophisticated models does not always lead to more accurate results (T. Rossetto, personal communication, 2013).

\subsection{Design for different levels of acceleration}

The lateral force method detailed in EC8 4.3.3.2 is used to design the buildings, using a linear structural model and a reduced elastic spectrum. Models with reduced stiffness are considered (as stated in EC8 3.2.2.5), to roughly take into account the beneficial effects of the nonlinearities (in particular the ductile behaviour of the structural elements). Since the considered structures are regular, the procedures are carried out using simplified 2D models.

The studied structure is first loaded with the gravity actions as in design using EC2. The vertical loads applied to the model are taken as a combination of permanent and variable loads. They are arranged to produce the most critical conditions for the structure. 
Then a lateral load is imposed to check the shear resistance of the building. Firstly, the spectral acceleration at the fundamental period of the structure is taken from the standard Type 1 design spectrum (EC8 3.2.2.5). The spectrum is computed for site class B, the most representative site class in Europe (Lemoine et al., 2012). It is fully constrained by the value of the required design (peak ground) acceleration (PGA, known in EC8 as $\mathrm{a}_{\mathrm{g}}$ ), corresponding to the anchoring spectral acceleration at $\mathrm{T}=0 \mathrm{~s}$. The computed spectral acceleration, the mass layout and the ductility class, which is employed within EC8 to define the capacity of the structure to dissipate energy (behaviour factor), are then used to compute the lateral load pattern to be applied to the building. The accidental torsion associated with small irregularities of the structure is also considered, as an extra multiplicative factor on the force pattern (EC8 4.3.3.2.4). These horizontal loads are then imposed on the numerical model and the lateral resistance is assessed by carrying out various checks, at micro and macro scales.

Firstly, the overall stability of the structure is verified by checking that the inter-story drift of each floor is not too large (EC8 4.4.3.2). In this study, this criterion was always respected up to $\mathrm{a}_{\mathrm{g}}$ of about $2 \mathrm{~m} / \mathrm{s}^{2}$. The limited influence of P-Delta effects is also assessed (EC8 4.4.2.2).

In addition to these macro-scale criteria, the adapted behaviour of each structural element is assessed. Freedom is given in EC2 to the design engineer to determine moment and shear forces when assessing the individual member resistance of each element of the structure. In this study, it has been decided to follow the procedures detailed in the guide by Bond et al. (2006).

The moment resistance is assessed at several locations over the beam (e.g. at mid-span and at member ends) by considering the material properties and the section geometry. When, the moment resistance is found to be inadequate, the area of longitudinal reinforcement is modified. In all cases, the reinforcement areal ratio should stay within the range of variation specified in EC2 9.2.1.1. The spacing of the reinforcement bars in the element sections should also be carefully monitored to ensure a good anchoring of the bars (EC8 5.6.2.2), and also to ensure that no contact occurs between adjacent bars (EC2 8.2). When these spacing criteria cannot be fulfilled, the concrete section must be increased. 
The criterion concerning the moment resistance was found to be the most critical for the beam design. The level of deflection (EC2 7.4) was also assessed, but it was sufficiently small once the aforementioned criterion was enforced. Finally, the beam shear resistance (EC2 6.2) has to be checked as well. This last condition affects only the stirrup spacing along the beam, which could be only accounted for in our models by changing the concrete confinement ratio longitudinally. Such a change would make the models much more complex for probably only a slight improvement in their accuracy. Hence, we did not consider this condition.

In the case of the columns, the moment resistance is similarly assessed [by computing the design moment with EC2 5.8.8.2 and then computing the minimum steel area based on Figures 9a to 9e in Bond et al. (2006)]. However, contrary to the case of beams, it appears that for the structure considered here, this criterion is not critical. In fact, the ruling criterion is the one detailed in EC8 4.4.2.3, ensuring that the columns are stronger than the beams. A last condition that ensures an adapted behaviour of the column in the case of biaxial loading is also considered (EC2 5.8.9), but had no influence over the element design in the present study.

The following example helps to clarify the main steps used to design the structure to different levels of PGA. Consider that a building has already been designed for a given $\mathrm{a}_{\mathrm{g}}$ and that its design has to be adjusted for a larger acceleration. Since the multiplicative factor on the horizontal load pattern is larger, a higher moment should be resisted in the beams and, hence, the steel area should be increased. Now suppose that the steel content in the beams was already critical, i.e. if the steel area is increased then the spacing criteria will no longer be respected. Consequently, the beam sections must be increased. The beams being then stronger, the dimensions of the columns should also be increased, to stay more resistant than the beams. Finally, as the whole building design is modified, all criteria should again be carefully checked and adjustments made.

Six versions of the structure for different $\mathrm{a}_{\mathrm{g}}$ were designed. One building is designed with EC2 only (i.e. $\mathrm{a}_{\mathrm{g}}=0 \mathrm{~m} / \mathrm{s}^{2}$, although this is not strictly true because of the condition of "plastic hinges in beams" is imposed by EC8 and not EC2), and four other buildings for the design accelerations of the French 
seismic zonation map $\left(0.7,1.1,1.7\right.$ and $\left.3.0 \mathrm{~m} / \mathrm{s}^{2}\right)$. Finally, a last structure is designed for $a_{g}=2.3 \mathrm{~m} / \mathrm{s}^{2}$, to fill the gap between the two highest accelerations in the French code (these zones being the zones of moderate seismicity in southern France and high seismicity in the French Antilles, respectively). All the structures were designed assuming medium ductility.

The beams and columns sections of these structures are detailed in Table 1. The concrete section is the same for the structures designed with $\mathrm{a}_{\mathrm{g}}$ up to $1.1 \mathrm{~m} / \mathrm{s}^{2}$. For higher design accelerations, the sections have been increased because the spacing between the rebars was no longer sufficient. Standard values are used for the reinforcement bars: $6,8,10,12,16,20,25,32 \mathrm{~mm}$ and so forth. Using standardized diameters leads to non-optimum designs because the necessary reinforcement areas cannot always be exactly obtained; a larger reinforcement area than required often needs to be used. A consequence is that two structures designed for different design accelerations can have the same sections, if the difference between the design levels is not large. This is what almost occurred with the structures designed for 0.7 and $1.1 \mathrm{~m} / \mathrm{s}^{2}$, whose design differs only for the upper area of reinforcement of the beams.

Our designs can be checked by comparing them with those proposed by Fardis et al. (2012) for a twostorey RC frame structure whose geometry is relatively close to ours. No information about the reinforcement content of the structural elements is provided in their article, but the main dimensions of the sections presented in their Table 1 gives valuable information. The building designed for an $\mathrm{a}_{\mathrm{g}}$ of $3 \mathrm{~m} / \mathrm{s}^{2}$ has the same column and beam dimensions but slight differences can be noticed for the structures designed for lower accelerations. This is probably because, contrary to their study, we allowed our structures to have slender columns.

\section{Development of fragility curves}

Nonlinear time histories analyses are carried out, using the finite element software Opensees (McKenna et al., 2000), to assess the seismic vulnerability of each structure. The plane-frame structures are modelled with force-based beam-column elements, each structural component being discretized by four elements (Neuenhofer and Filippou, 1998). The finite elements are discretized by 
three integration points over their lengths. The uniaxial material Concrete 06 is used for the concrete and Steel01 for the reinforcement steel. Table 2 and Table 3 detail the properties of these materials. In addition to the material nonlinearities, geometric nonlinearities (P-Delta effects) are also taken into account, the corotational transformation being used for the columns.

Several methods have been used to derive fragility functions from dynamic time-history analysis. Here the approach called "linear regression on a cloud" by Baker (2007) is followed. In this technique a set of unscaled accelerograms (see below) are used as input. All the used accelerograms being independent, a great diversity in their spectral content is ensured. In this technique, a least-square optimisation leads to a robust relation between the maximum transient drift and the intensity measure (here, PGA), from which the fragility function parameters are finally obtained, assuming lognormal distributions. This method is particularly useful for higher damage states, for which the data are scarce, because the obtained relation could be extrapolated (although this is a source of additional uncertainty).

\subsection{Strong-motion records}

The structures are subjected to a set of unscaled accelerograms selected from the Internet Site for European Strong-motion Data (Ambraseys et al., 2004) and from the PEER NGA database (Chiou et al., 2008). Records have been firstly selected by considering magnitudes between 4.5 and 6.5 and source-to-site distances up to $100 \mathrm{~km}$, which roughly covers the earthquake scenarios of most interest for much of Europe. A further selection based on the PGA has then been considered to remove many weak records that do not damage the structures. Figure 2 confirms that the distribution of PGA is relatively uniform. In total, 183 records are used. This is a sufficient number for deriving reliable fragility functions when using a regression-based method (Gehl et al., 2014).

\subsection{Damage thresholds}

To characterize the damage state at the end of the dynamic simulations, a standard inter-storey drift criterion at each floor is considered. It is common to compute the drift corresponding to each limit state by exploiting the results of a static push-over analysis. In this study, the standard method 
proposed by Milutinovic and Trendafiloski (2003) was tested. In this approach, the drift thresholds for each damage state are derived from the yield drift, corresponding to the first occurrence of plasticity, and the ultimate drift, corresponding to a $15 \%$ drop in strength. Both values are read from the pushover curve. Figure 3 shows the evolution of the base shear, normalized by its peak value, with the drift, for all the considered structures. Since the curves have a similar shape, using the same drift threshold for all the structures is a valid simplification.

The structures show high ductilities, the drop of $15 \%$ of the maximum base-shear appearing after a drift of about $10 \%$. Consequently, the use of the aforementioned method would lead to unusual and probably unrealistic drift thresholds. Consequently, a different approach was finally chosen: the generic thresholds proposed by Ghobarah (2004) for ductile moment-resisting frames. There is considerable uncertainty in the assessment of drift thresholds, particularly for the highest damage states (e.g. collapse), and other thresholds could be envisaged. As proposed by Crowley et al. (2011) and Gehl et al. (2013), results for only two damage states are presented: damage state D1, which is termed 'yield', and D4 and D5 that are merged into 'collapse'. Both these damage levels are interesting for the risk-targeting approach. Luco et al. (2007) uses the collapse damage state for their US risk-targeting approach, whereas Douglas et al. (2013), who focused on mainland France, pointed out that yielding might be more appropriate for countries of moderate seismic hazard.

\subsection{Results}

Lognormal cumulative distributions are assumed for the fragility curves. The obtained parameters are shown in Table 4 and the corresponding curves are plotted in Figure 4. As expected, the building designed for the highest accelerations are the least vulnerable. Nevertheless, the vulnerabilities of the buildings designed for $\mathrm{a}_{\mathrm{g}}$ less than or equal to $1.1 \mathrm{~m} / \mathrm{s}^{2}$ are almost the same. This is unexpected, and suggests that the building designed using only EC2 already presents adequate resistance against moderate earthquake loading. For these low accelerations, the additional criteria of EC8 are not very restrictive and the designed structures are not greatly modified from those obtained only considering EC2. It should be noted, however, that this finding may not hold for irregular structures, other 
geometries or materials. The value of the standard deviation seems quite high for the three structures designed for moderate accelerations. As Douglas et al. (2013) and Chapter 21 of the ASCE Standard $7-10$ assumed standard deviations of 0.5 and 0.6 , respectively, for fragility functions corresponding to

224 the entire new building stock we would expect that fragility functions corresponding to a single geometry and building material should present lower standard deviations. In addition, we did not consider variability in the material (steel and concrete) properties, which could have increased the standard deviations of the fragility functions; although the contribution of this variability to the total standard deviation is usually much lower than the contribution of the strong-motion variability (e.g. Kwon and Elnashai, 2006).

\subsection{Comparison with previous results}

To check the obtained fragility functions, a comparison with curves developed in previous studies for similar structures is made here. To determine the most appropriate functions for this comparison, the software Fragility Function Manager 2.0 developed during the FP7 Syner-G project (Silva et al., 2013) is used. A search considering only low-rise RC structures within this database was made. The most appropriate functions were then chosen manually. It is worth noting that many of the functions returned by the original search correspond to studies for Turkish buildings but only one of these functions is considered here to avoid being too geographically specific. Three fragility functions were finally chosen: two are based on numerical simulations (Kirçil and Polat, 2006; Kwon and Elnashai, 2006) and one based on empirical data (Rossetto and Elnashai, 2003).

The first comparison is made for a three-storey RC frame designed using the 1975 Turkish seismic code, whose seismic vulnerability was assessed by Kirçil and Polat (2006), using Incremental Dynamic Analyses (IDA) and twelve artificial ground motions. The design acceleration is not given in the article, but the building is described as typical for Istanbul. The 1975 Turkish code does not directly define design accelerations but a "seismic zone coefficient" varying between 0.03 and 0.1 depending on the zone. If this coefficient can be identified as the design acceleration, then the design level of the 1975 code corresponding to Istanbul can be obtained. As the city is in zone 2, the design 
PGA is $0.08 \mathrm{~g}\left(0.8 \mathrm{~m} / \mathrm{s}^{2}\right)$, which seems quite low. In the 1997 code an effective ground acceleration coefficient is used; for Istanbul it is equal to $3.0 \mathrm{~m} / \mathrm{s}^{2}$ (Sezen et al., 2000). If this last observation is disregarded, the structure designed for $\mathrm{a}_{\mathrm{g}}=0.7 \mathrm{~m} / \mathrm{s}^{2}$ seems the best candidate for the comparison. The corresponding function is almost the same as that for $\mathrm{a}_{\mathrm{g}}=0 \mathrm{~m} / \mathrm{s}^{2}$; see Figure 5 (for yield) and Figure 6 (for collapse). The match seems reasonable given the differences between the two structures and codes. The fragility functions of the present study show, nevertheless, a larger standard deviation. As stated above, the variability of our results could be too large. Nevertheless, the lower variability of the compared functions could be due to the use of IDA and fewer ground-motion records.

The next comparison is with the functions of Kwon and Elnashai (2006), who quantify the fragility of a three-storey RC moment resisting frame designed only for gravity loads. The building is said to be representative of central northern Europe and USA and is consequently well adapted for this comparison. Kwon and Elnashai (2006) divide their ground-motion records into three datasets depending on their PGA/PGV ratio. According to their classification, most of our accelerograms (54\%) present high $\mathrm{PGA} / \mathrm{PGV}$ ratios, the rest of them being equally shared in the two remaining categories (24\% present medium ratios and $22 \%$ low ratios). To obtain reference fragility functions more adapted to the particularities of our dataset, a weighted sum of the fragility functions of Kwon and Elnashai (2006) is first computed, and the resulting functions is then idealized by a lognormal function. The fragility curves corresponding to the three ratio categories (dashed blue lines), and the combined idealized functions (solid blue lines) are displayed in Figure 5 (for yield) and Figure 6 (for collapse). Once again, a good fit is noticed with our fragility functions (see curves $a_{g}=0.0 \mathrm{~m} / \mathrm{s}^{2}$ ); the fit is particularly good for yield. The standard deviation of our fragility functions for collapse damagestate is again larger than in the functions of Kwon and Elnashai (2006).

A last comparison is carried out with functions obtained by a different procedure: empirical functions obtained by Rossetto and Elnashai (2003) from processing post-event assessments of over 340000 structures realized after 19 earthquakes. Contrary to the two previous comparisons, the fragility functions of Rossetto and Elnashai (2003) are not expressed as a lognormal cumulative distribution, but are given as list of values. Their damage levels "slight" and "extensive" are used for the 
comparison with our curves. In Figure 5 (for yield) and Figure 6 (for collapse), it can be observed that the damage probabilities from Rossetto and Elnashai (2003) are much lower than all the other functions, e.g. the yield curve of Rossetto and Elnashai (2003) is similar to the collapse curves of the other studies. This problem with their empirical curves is noted by Rossetto and Elnashai (2005) who, after comparing their empirical and analytical curves (from their 2005 article), wrote: 'these observations give rise to substantial doubt as regards the reliability of observation-based vulnerability functions and confirm the importance of analytical methods for the generation of fragility curves'.

In conclusion, two of the fragility functions considered here fit the functions obtained in the present study reasonably well. Nevertheless, the standard deviations of these functions, particularly those for the collapse damage state, are lower than the ones obtained in this study. This discrepancy might be explained by differences in the methods used to obtain the fragility functions. The higher spectral variability of the records used in this study could explain part of the observed differences. On the other hand, the functions presented in Rossetto and Elnashai (2003) show a poor match with ours. This highlights the great uncertainty in fragility functions that can be found in the literature.

\section{Conclusions}

Within the risk-targeting approach it is assumed that the probability of collapse when the observed PGA equals $\mathrm{a}_{\mathrm{g}}$ is constant for buildings designed against different acceleration levels. This conjecture is evaluated in Table 5, where the probabilities of yield and collapse at $a_{g}$ are listed for all the structures studied in the present article. The probability of yielding for a structure subjected to a PGA equal to $a_{\mathrm{g}}$ varies between $0.14\left(\mathrm{a}_{\mathrm{g}}=0.7 \mathrm{~m} / \mathrm{s}^{2}\right)$ and $0.85\left(\mathrm{a}_{\mathrm{g}}=3 \mathrm{~m} / \mathrm{s}^{2}\right)$ whereas the probability of collapse for a structure subjected to a PGA equal to $\mathrm{a}_{\mathrm{g}}$ varies between $1.7 \times 10^{-7}\left(\mathrm{a}_{\mathrm{g}}=0.7 \mathrm{~m} / \mathrm{s}^{2}\right)$ and $1.0 \times 10^{-5}$ $\left(\mathrm{a}_{\mathrm{g}}=3 \mathrm{~m} / \mathrm{s}^{2}\right.$ ). In Douglas et al. (2013), a value of $10^{-5}$ is proposed for the probability of collapse given a PGA equal to the design value when conducting risk targeting. This value seems roughly suitable for all the structures, except for the one designed for $\mathrm{a}_{\mathrm{g}}=0.7 \mathrm{~m} / \mathrm{s}^{2}$. This exception is related to the similar vulnerabilities presented by structures designed for $\mathrm{a}_{\mathrm{g}} \leq 1.1 \mathrm{~m} / \mathrm{s}^{2}$. It suggests that designing regular structures against low accelerations is not useful when the overall design is controlled by modern 
(non-seismic) codes, such as EC2. Douglas et al. (2013) suggested the idea of targeting the 'yield' damage state rather than 'collapse' in areas of moderate seismicity. Again, Table 5 seems to support this idea. A probability of yielding when a structure is subjected to its design PGA of $40 \%$ to $80 \%$ could be considered for that purpose.

In conclusion, the present study confirms the hypotheses made in the risk-targeting approach. This is an important stage toward the generation of new seismic design maps for Europe. Nevertheless the limits of the study should be carefully considered. Specifically, only a single characteristic structure is considered here; the next step could be to generalize the developed method for other structural geometries and types. In particular, it would be interesting to see if the structural type has a big impact on the fragility curve. If it does, then the current risk-targeting approach is not appropriate but would require a series of maps to be produced per building type.

One could also take advantage of the designed structures to carry out economic studies on the additional cost of seismic reinforcement. This could lead to design using a cost-benefit point of view, which could be useful in improving the efficiency of design codes.

\section{Acknowledgements}

This article was supported by the internal BRGM research programme VULNERISK/MULTIRISK/MIR2 2012 and 2013. We thank Pierre Gehl for his help in conducting the analyses presented here and his comments on an earlier version of this article. Finally, we thank the two anonymous reviewers for their constructive and detailed comments on a previous version of this article.

\section{References}

Ambraseys NN, Douglas J, Sigbjörnsson R, Berge-Thierry C, Suhadolc P, Costa G and Smit PM (2004), Dissemination of European Strong-Motion Data, vol 2 using Strong-Motion Datascape 
Navigator, CD-ROM collection, engineering and Physical Sciences Research Council, United Kingdom.

Baker J (2007), Probabilistic structural response assessment using vector-valued intensity measures, Earthquake Engineering and Structural Dynamics, 36, 1861-83.

Bond AJ, Brooker O, Harris AJ, Harrison T, Moss RM, Narayanan RS and Webster R (2006), How to design concrete structures using Eurocode 2, The Concrete Centre, London, ISBN 1-904818-4-1.

CEN (2004a), Eurocode 2, Design of concrete structures, Part 1-1: General rules and rules for buildings, BS EN 1992-1-1: 2004, Brussels: European Committee of standardization.

CEN (2004b), Eurocode 8, Design of structures for earthquake resistance, Part 1: general rules, seismic actions and rules for buildings, BS EN 1998-1: 2004, Brussels: European Committee of standardization.

Chiou B, Darragh R, Gregor N and Silva W (2008), NGA Project Strong-Motion Database, Earthquake Spectra, 24, 23-44.

Crowley H, Colombi M, Silva V, Ahmad N, Fardis M, Tsionis G, Papailia A, Taucer F, Hancilar U, Yakut A, Erberik M (2011), Fragility functions for common RC building types in Europe, Tech. Rep. D3.1, Systemic Seismic Vulnerability and Risk Analysis for Buildings, Lifeline Networks and Infrastructures Safety Gain (SYNER-G), Project of the EC Framework Programme 7.

Douglas J, Ulrich T and Negulescu C (2013), Risk-targeted seismic design maps for mainland France, Natural Hazards, 65, 1999-2013, DOI: 10.1007/s11069-012-0460-6.

Fardis M, Papailia A and Tsionis G (2012), Seismic fragility of RC framed and wall-frame buildings designed to the EN-Eurocodes, Bulletin of Earthquake Engineering, 10(6), 1767-1793.

Gehl P, Seyedi DM and Douglas J (2013), Vector-valued fragility functions for seismic risk evaluation, Bulletin of Earthquake Engineering, 11(2), 365-384, DOI: 10.1007/s10518-012-9402-7. 
347 Gehl P, Douglas J and Seyedi D (2014), Influence of the number of dynamic analyses on the accuracy

348 of structural response estimates, Earthquake Spectra, in press, DOI: 10.1193/102912EQS320M.

349 Ghobarah A (2004), On drift limits with different damage levels, In: Proceedings of International

350 Workshop on Performance-based seismic design concepts and implementation, June 28th - July 1st,

3512004 , Bled, Slovenia.

352 Kirçil MS and Polat Z (2006), Fragility analysis of mid-rise R/C frame buildings, Engineering

353 Structures, 28(9), 1335-1345.

354 Kwon OS and Elnashai A (2006), The effect of material and ground motion uncertainty on the seismic

355 vulnerability curves of RC structure, Engineering Structures, 28, 289-303

Lemoine A, Douglas J and Cotton F (2012), Testing the applicability of correlations between topographic slope and VS30 for Europe, Bulletin of the Seismological Society of America, 102(6), 2585-2599, DOI: 10.1785/0120110240.

Luco N, Ellingwood BR, Hamburger RO, Hooper JD, Kimball JK and Kircher CA (2007), Risktargeted versus current seismic design maps for the conterminous United States, In: SEAOC 2007 Convention Proceedings.

Luco N (2009), Preparation of new seismic design maps for building codes, In: 2009 COSMOS Technical Session.

McKenna F, Fenves GL, Scott MH and Jeremic B (2000), Open System for Earthquake Engineering Simulation (OpenSees), Pacific Earthquake Engineering Research Center, University of California, Berkeley, CA.

Milutinovic Z and Trendafiloski G (2003), WP4 vulnerability of current buildings, chapter 4.2. AUTH WP4 WG Approach, Tech rep, Risk-UE: An advanced approach to earthquake risk scenarios with applications to different European towns, European Commission. 
370 Neuenhofer A and Filippou FC (1998), Geometrically nonlinear flexibility-based frame finite element,

371 ASCE Journal of Structural Engineering, 124(6), Paper 16537, 704-711.

372 Sezen H, Elwood KJ, Whittaker AS, Mosalam KM, Wallace JW and Stanton JF (2000), Structural

373 Engineering Reconnaissance of the August 17, 1999 Earthquake: Kocaeli (Izmit), Turkey, Chapter 2:

374 Evolution of Seismic Building Design Practice in Turkey, PEER report.

375 Silva V, Crowley H and Colombi M (2013), Fragility Function Manager 2.0, FP7 SYNER-G

376 (Systemic Seismic Vulnerability and Risk Analysis for Buildings, Lifeline Networks and 377 Infrastructures Safety Gain).

378 Spacone E, Filippou FC and Taucer FF (1996), Fiber beam-column model for non-linear analysis of 379 RC frames: Part I. formulation, Earthquake Engineering and Structural Dynamics, 25, 711-725. 
381 Table 1. Geometry of the sections designed with EC2 and EC8.

\begin{tabular}{|c|c|c|c|c|c|}
\hline & Beams & & & Columns & \\
\hline $\mathbf{a}_{\mathrm{g}}$ & $\operatorname{dim}(H \times B)$ & upper reinf. & lower reinf. & $\operatorname{dim}(\mathbf{H} \times \mathbf{B})$ & reinf. \\
\hline $\mathrm{m} / \mathrm{s}^{2}$ & $\mathbf{m} \times \mathbf{m}$ & $\mathbf{n b} \times \mathbf{m m}\left(\mathbf{m m}^{2}\right)$ & & $\mathbf{m} \times \mathbf{m}$ & $\mathbf{n b} \times \mathbf{m m}\left(\mathbf{m m}^{2}\right)$ \\
\hline 0.0 & $0.35 \times 0.30$ & $6 \times 16(1206)$ & $5 \times 10(393)$ & $0.35 \times 0.35$ & $5 \times 20(1571)$ \\
\hline 0.7 & $0.35 \times 0.30$ & $3 \times 25(1473)$ & $6 \times 10(471)$ & $0.35 \times 0.35$ & $4 \times 25(1963)$ \\
\hline 1.1 & $0.35 \times 0.30$ & $5 \times 20(1571)$ & $5 \times 12(565)$ & $0.35 \times 0.35$ & $4 \times 25(1963)$ \\
\hline 1.7 & $0.35 \times 0.30$ & $6 \times 20(1885)$ & $4 \times 16(804)$ & $0.40 \times 0.40$ & $4 \times 25(1963)$ \\
\hline 2.3 & $0.35 \times 0.30$ & $4 \times 25(1963)$ & $3 \times 20(942)$ & $0.45 \times 0.45$ & $6 \times 25(2945)$ \\
\hline 3.0 & $0.40 \times 0.35$ & $3 \times 32(2413)$ & $4 \times 16(804)$ & $0.45 \times 0.45$ & $6 \times 25(2945)$ \\
\hline
\end{tabular}

382

383 Table 2. Reinforcement steel properties considered (Steel01), where $F_{y}$ is the yield strength, $E_{0}$ the 384 initial young modulus and $\mathrm{b}$ the strain-hardening ratio.

\begin{tabular}{lll}
\hline & value & unit \\
\hline $\mathbf{F}_{\mathbf{y}}$ & 575 & $\mathrm{MPa}$ \\
$\mathbf{E}_{\mathbf{0}}$ & $2.00 \times 10^{5}$ & $\mathrm{MPa}$ \\
$\mathbf{b}$ & 0.001 & \\
\hline
\end{tabular}


392

393 394

Table 3. Concrete properties considered (Concrete06), where $f_{c}$ is the compressive strength, $e_{0}$ the strain at compressive strength, $E_{c}$ the Young's modulus and $f_{c r}$ the tensile strength, which is set to zero since it has little influence on the global behaviour of the element and it generates numerical instabilities. The other numerical properties of the model (shape factors) are not detailed, but can be easily deduced from the parameters shown.

\begin{tabular}{llll}
\hline & & value & unit \\
\hline $\mathbf{f}_{\mathbf{c}}$ & (conf.) & -38.9 & $\mathrm{MPa}$ \\
$\mathbf{e}_{\mathbf{0}}$ & (conf.) & $-4.14 \times 10^{-3}$ & \\
$\mathbf{f}_{\mathbf{c}}$ & (unconf.) & -33.0 & $\mathrm{MPa}$ \\
$\mathbf{e}_{\mathbf{0}}$ & (unconf.) & $-2.07 \times 10^{-3}$ & \\
$\mathbf{E}_{\mathbf{c}}$ & & $3.15 \times 10^{4}$ & $\mathrm{MPa}$ \\
$\mathbf{f}_{\text {cr }}$ & & 0 & $\mathrm{MPa}$ \\
\hline
\end{tabular}

Table 4. Median $(\mu)$ and standard deviation $(\sigma)$ of the lognormal fragility curves for yielding and collapse.

\begin{tabular}{|c|c|c|c|c|}
\hline & yielding & & collapse & \\
\hline$a_{g}\left(m / s^{2}\right)$ & $\mu\left(\mathrm{m} / \mathrm{s}^{2}\right)$ & $\boldsymbol{\sigma}$ & $\mu\left(\mathbf{m} / \mathbf{s}^{2}\right)$ & $\sigma$ \\
\hline 0.0 & 1.12 & 0.51 & 8.79 & 0.51 \\
\hline 0.7 & 1.20 & 0.50 & 8.77 & 0.50 \\
\hline 1.1 & 1.26 & 0.49 & 8.78 & 0.49 \\
\hline 1.7 & 1.53 & 0.44 & 10.07 & 0.44 \\
\hline 2.3 & 1.72 & 0.41 & 11.24 & 0.41 \\
\hline 3.0 & 2.03 & 0.37 & 14.59 & 0.37 \\
\hline
\end{tabular}


397 Table 5. Probability of damage at $\mathrm{PGA}=\mathrm{a}_{\mathrm{g}}$ for different values of $\mathrm{a}_{\mathrm{g}}$.

\begin{tabular}{lll}
\hline $\mathbf{a}_{\mathrm{g}}\left(\mathbf{m} / \mathbf{s}^{2}\right)$ & yield & collapse \\
\hline 0.7 & 0.139 & $1.73 \times 10^{-7}$ \\
1.1 & 0.392 & $9.80 \times 10^{-6}$ \\
1.7 & 0.592 & $2.58 \times 10^{-5}$ \\
2.3 & 0.763 & $5.23 \times 10^{-5}$ \\
3.0 & 0.854 & $1.04 \times 10^{-5}$ \\
\hline
\end{tabular}

398

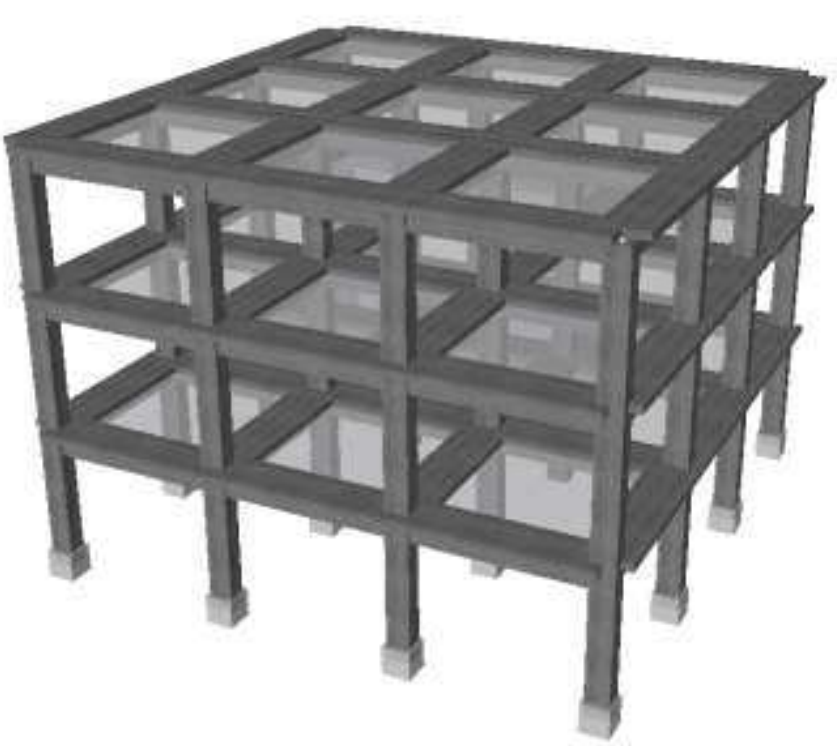

399

400 Figure 1.3D geometry of the structure (a three storey-three bay-four frame building) considered here.

401 The building being regular, a 2D representation of the structure (one frame) is used in the design and 402 the dynamic analyses process. 


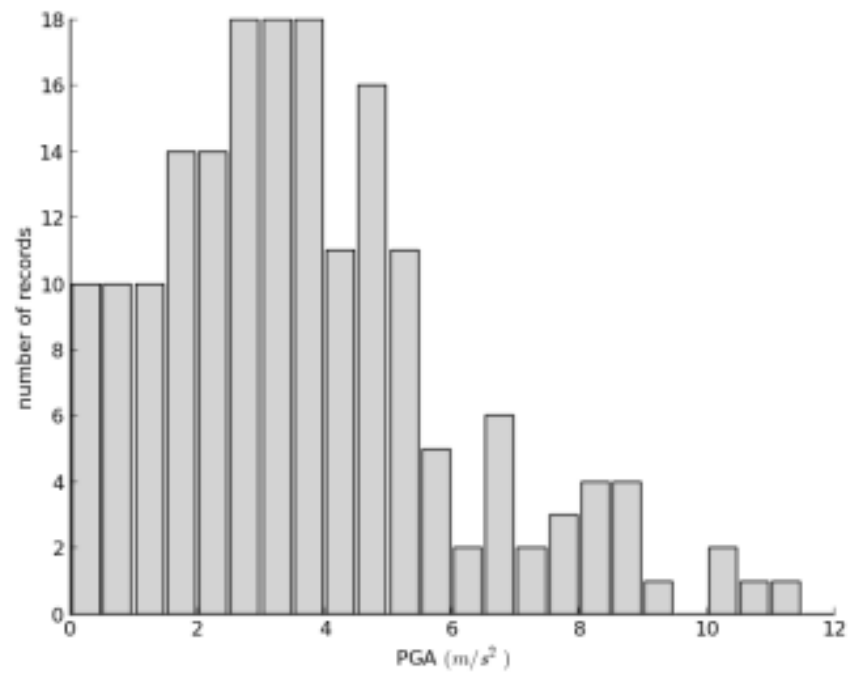

405 Figure 2. Histogram showing the PGAs for the set of accelerograms.

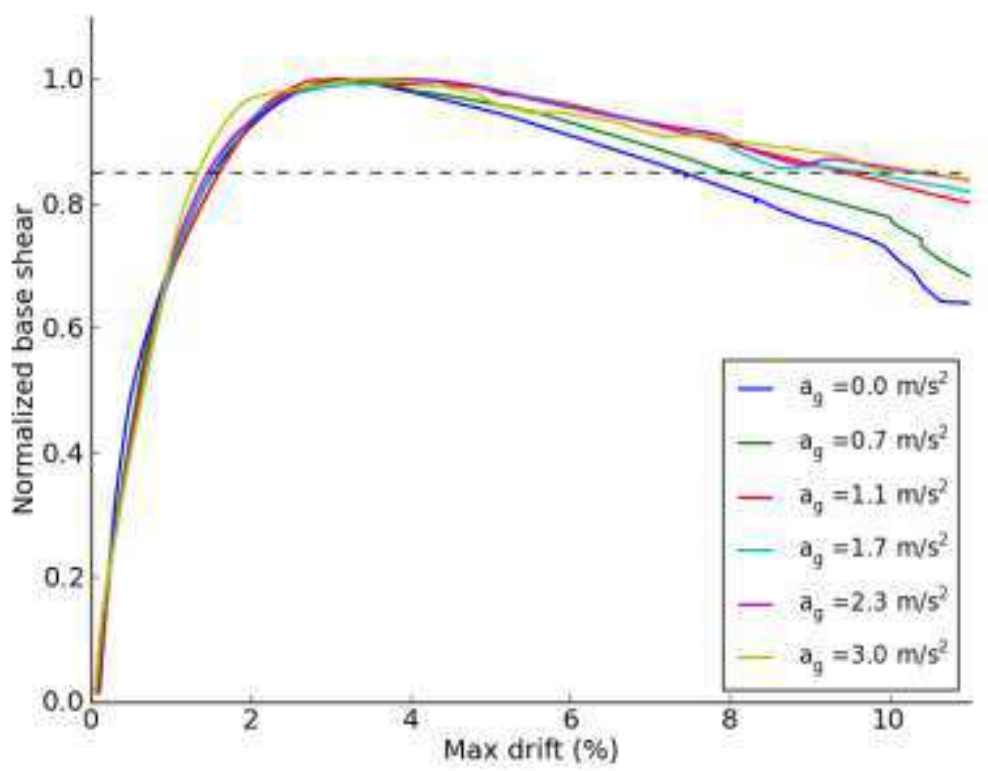

406

407 Figure 3 Normalised push-over curve for the six versions of the structure. The $15 \%$ drop, which gives an idea of the structures' ductility, is shown by the dashed line. 

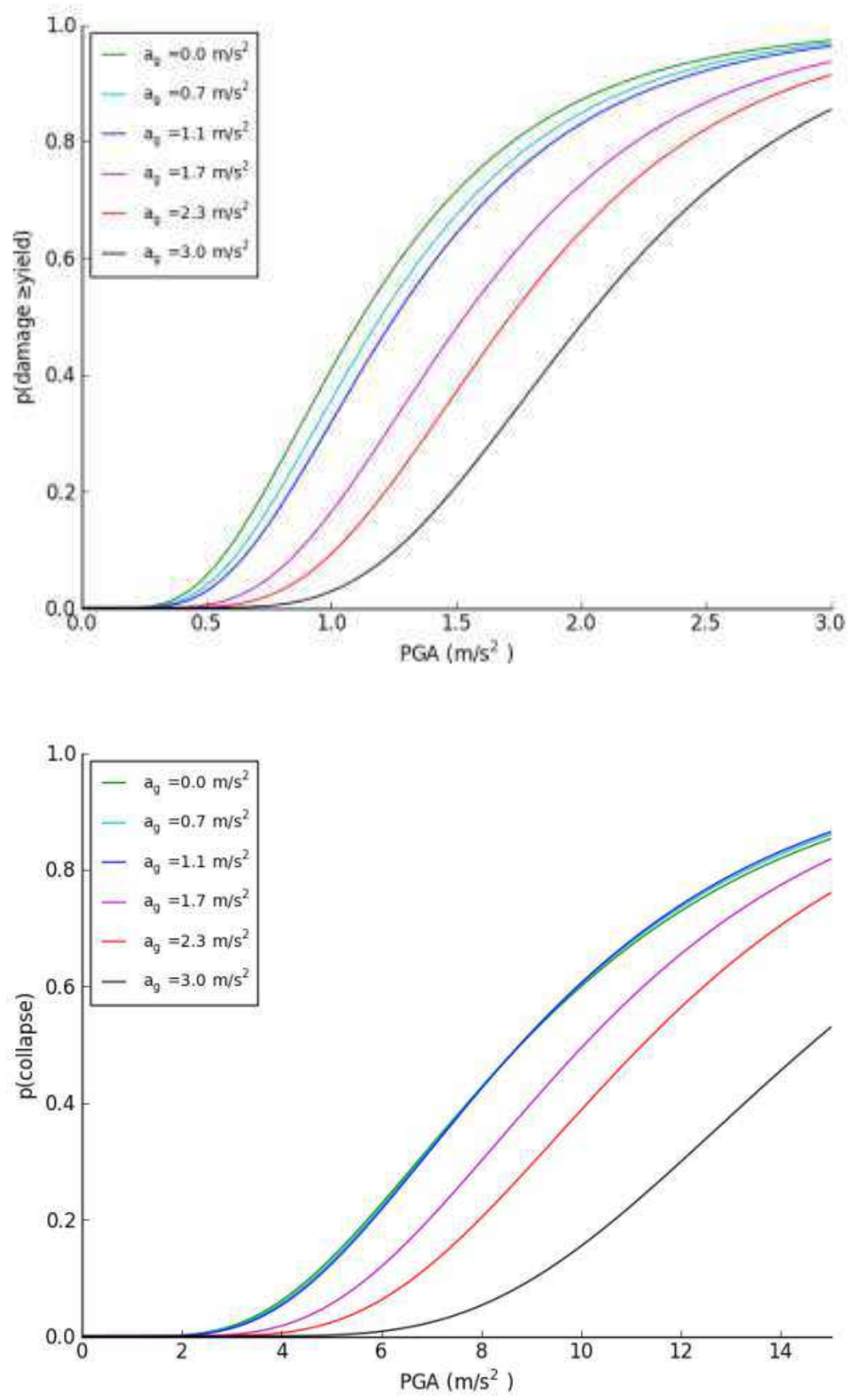

411

412 Figure 4. Fragility curves of the six designed structures: (a) yield and (b) collapse. Note that the curves 413 for $\mathrm{a}_{\mathrm{g}} \leq 1.1 \mathrm{~m} / \mathrm{s}^{2}$ are almost the same. 


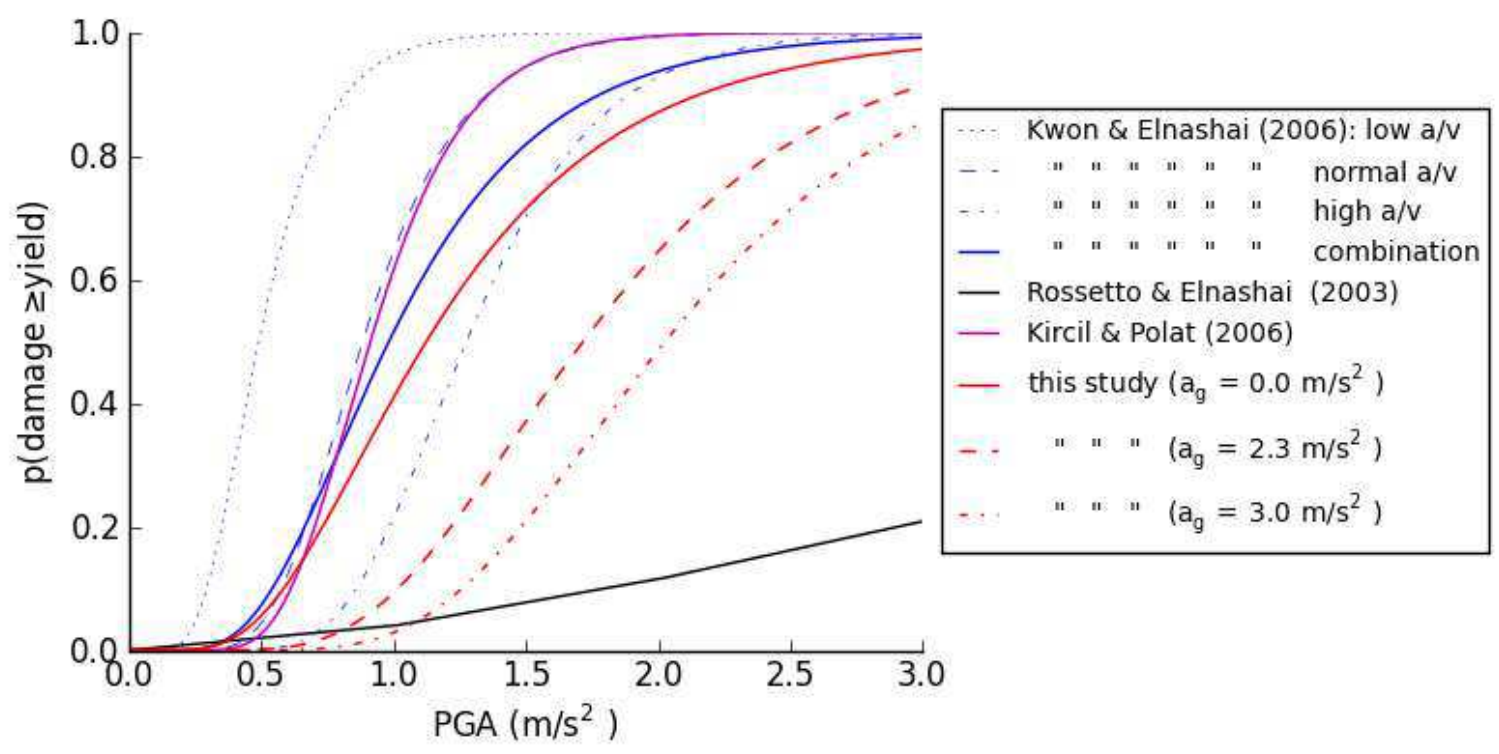

415 Figure 5: Comparison of the obtained fragility functions with selected fragility curves from the 416 literature for the yield damage state. In Kwon \& Elnashai (2006) the building is designed only for 417 gravity loads so the functions with $\mathrm{a}_{\mathrm{g}}=0 \mathrm{~m} / \mathrm{s}^{2}$ seem the best candidate for comparison; for Kirçil \& 418 Polat (2006) we determined that the best candidate for comparison is the function with $\mathrm{a}_{\mathrm{g}}=0.7 \mathrm{~m} / \mathrm{s}^{2}$, 419 which is almost the same as the function for $a_{g}=0 \mathrm{~m} / \mathrm{s}^{2}$. Finally, the curves of Rossetto and Elnashai 420 (2003) apply for the whole RC building stock so all the displayed functions are eligible for 421 comparison. 


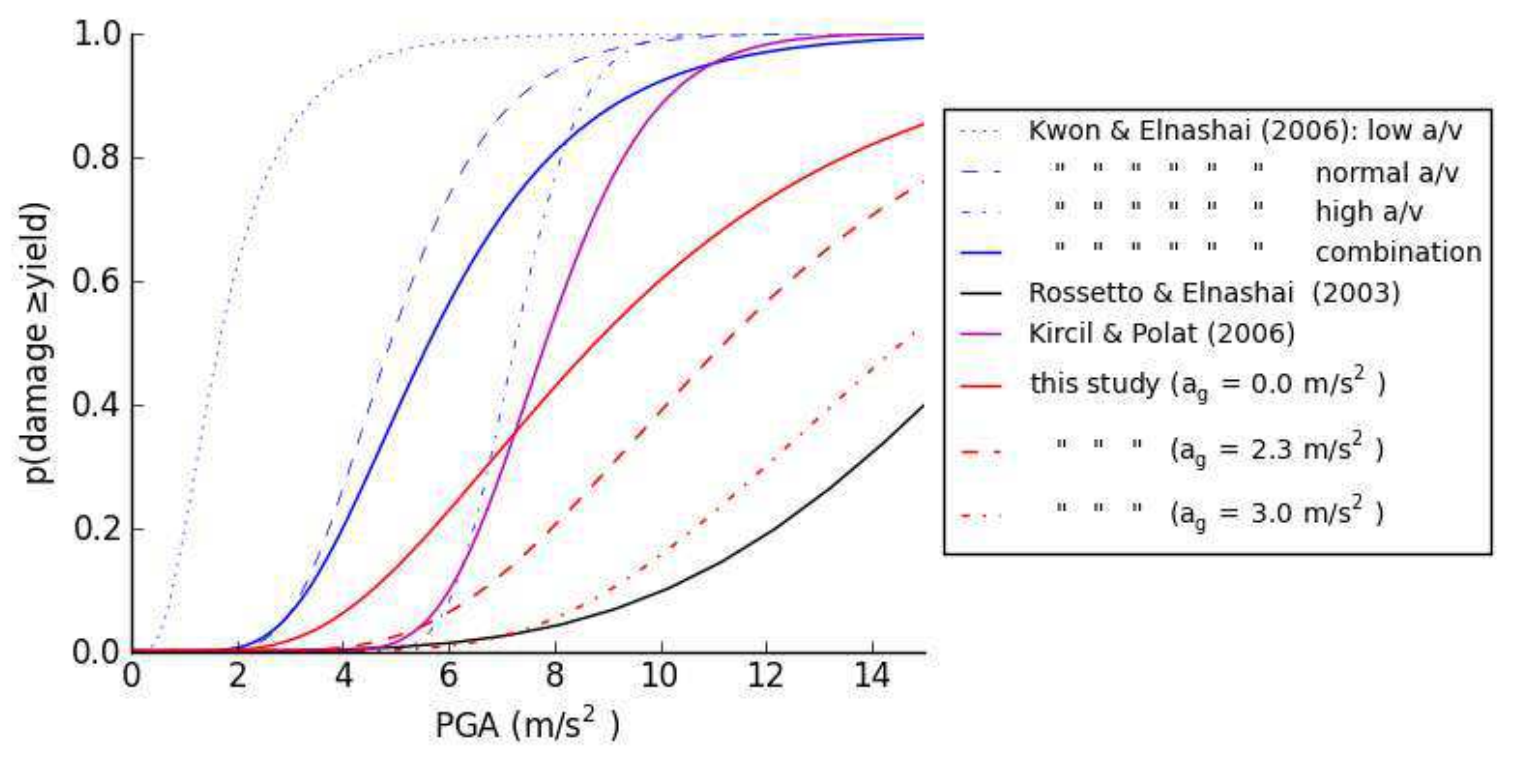

423

424 Figure 6: Comparison of the obtained fragility functions with selected fragility curves from the 425 literature for the collapse damage state. 